\title{
Composição e distribuição da vegetação herbácea em três áreas com fisionomias distintas na Praia do Peró, Cabo Frio, RJ, Brasil ${ }^{1}$
}

\author{
Sandra Zorat Cordeiro ${ }^{2}$
}

Recebido em 19/05/2004. Aceito em 01/03/2005

\begin{abstract}
RESUMO - (Composição e distribuição da vegetação herbácea em três áreas com fisionomias distintas na Praia do Peró, Cabo Frio, RJ, Brasil). A composição e a distribuição da vegetação herbácea da Praia do Peró foram caracterizadas em três áreas com topografias e fisionomias distintas, pelo método de parcelas. As três áreas são ocupadas pela comunidade psamófila-reptante, visualmente dividida em duas regiões: frontal, com espécies estoloníferas e suculentas, e posterior, com predomínio de espécies graminóides. Foram amostradas 38 espécies, das quais Paspalum maritimum Trim, Ipomoea imperati (Vahl.) Griseb, Ipomoea pes-caprae (L.) Sweet, Sporobolus virginicus (L.) Kunth e Panicum racemosum (Beauv.) Spreng. alcançaram os maiores valores de importância (VI). A topografia do ambiente, intimamente relacionada com a dinâmica de ondas de maré e tempestades, com aporte de areia oriunda dos ventos e das marés e com a ação antrópica, não influencia a distribuição das espécies vegetais encontradas, sendo considerada apenas como um componente influente na paisagem, estabelecido em conjunto com a comunidade vegetal, sendo esta última fortemente determinada pela distância em que se encontra em relação ao mar.
\end{abstract}

Palavras-chave: fitossociologia, dunas, restinga, comunidades vegetais, topografia

\begin{abstract}
Composition and distribution of herbaceous vegetation in three areas of different aspect in Praia do Peró, Cabo Frio, Rio de Janeiro State, Brazil). The composition and the distribution of herbaceous vegetation of Praia do Peró were characterized in three areas with different topographic and aspect, by using the method of quadrats. The three areas are occupied by the creeping-psamophyte community, being visually divided into two regions: frontal, with stolonipherae and succulent species, and posterior, with predominance of grass species. Thirty-eight species were sampled, from which Paspalum maritimum Trim, Ipomoea imperati (Vahl.) Griseb, Ipomoea pes-caprae (L.) Sweet, Sporobolus virginicus (L.) Kunth and Panicum racemosum (Beauv.) Spreng. attained the highest values of importance (VI). The topography, intimately related with the dynamics of tidal waves and storms, with the deposit of sand brought by the winds and tides, and with the human action, doesn't influence the distribution of the vegetal species found, being considered only as a component that influences the landscape, established together with the vegetal community, being the latter strongly determined by the distance of the sea.
\end{abstract}

Key words: phytosociology, dunes, restinga, plant communities, topography

\section{Introdução}

$\mathrm{Na}$ costa brasileira, as restingas destacam- se pelas grandes áreas que ocupam e por formarem um ecossistema com estreita relação com o mar, gerando um mosaico de comunidades vegetais associadas à geomorfologia local e adaptadas às condições físicas e ambientais (Araujo 1992; Henriques et al.1986; Thomaz \& Monteiro 1992). Como parte deste mosaico, a vegetação de dunas praianas merece atenção especial devido à intensa modificação a que está sujeita, ao alto potencial biológico por abrigar espécies endêmicas (FEEMA 1988), ao papel que desempenha na preservação da morfologia costeira (Cordazzo \& Seeliger 1987) e na configuração paisagística (Britto \& Noblick 1984; Silva \& Somner 1984), e às condições adversas que as dunas oferecem ao crescimento e desenvolvimento da vegetação (Lacerda et al. 1993). No sudeste brasileiro, a vegetação de dunas é diversas vezes caracterizada por apresentar dois tipos de formações, a halófila e a psamófila-reptante, podendo ou não ser distinguida uma da outra (Almeida \& Araujo 1997; Menezes \& Araujo 1999), distintas a partir da distribuição em faixas paralelas ao mar, compondo uma zonação, determinada principalmente pela distância em relação a este (Rawitscher 1944; Dansereau 1947) e pela presença de espécies características (Araujo \& Henriques 1984; Pereira 1990). Além da zonação e da composição florística, outros fatores podem atuar na distribuição da vegetação e caracterização da comunidade, como a concentração de nutrientes no solo (Menezes \& Araujo 2000), profundidade do lençol

\footnotetext{
1 Parte da Dissertação de Mestrado da Autora

2 Rua Santo Amaro 75, apto. 306, Glória, CEP 22211-130, Rio de Janeiro, RJ, Brasil (sandrazorat @ hotmail.com)
} 
freático (Earle \& Kershaw 1989), deposição de salsugem (Seeliger 1992) e posição topográfica (Cordazzo \& Costa 1989).

Este trabalho procura caracterizar, por intermédio da análise de parâmetros fitossociológicos, as formações vegetais herbáceas que ocorrem em três áreas fisionomicamente distintas nas dunas da Praia do Peró, em Cabo Frio, no Rio de Janeiro, quanto à sua composição florística e posição topográfica, verificando os processos que influenciam sua distribuição e determinam a paisagem.

\section{Material e métodos}

Área de estudo - A Praia do Peró localiza- se no

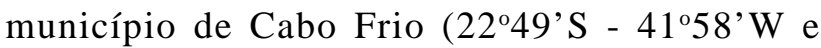
$22^{\circ} 52^{\prime} \mathrm{S}$ - 41 $\left.{ }^{\circ} 59^{\prime} \mathrm{W}\right)$, Estado do Rio de Janeiro, Brasil. Possui cerca de $6 \mathrm{~km}$ de extensão, ao longo dos quais se projeta uma escarpa praial, com alturas variáveis (de 0,5 a 4,0 m), formada pela ação de ondas de tempestade ou forças de marés de sizígia na faixa antedunal, às quais esta faixa está constantemente sujeita. Sobre a escarpa, para o interior, o terreno é formado por dunas eólicas, cobertas por vegetação que, ao longo da praia, assume diferentes fisionomias. Na região frontal, as dunas são ocupadas por vegetação herbácea, formada por espécies de folhas grossas, suculentas, com caule prostrado ou subterrâneo. Esta vegetação torna-se cada vez mais distinta conforme se observam processos de formação de dunas cada vez mais afastadas do mar, local também chamado de zona de transição entre a vegetação psamófila-reptante e a vegetação arbustiva, onde ocorre diminuição na ocupação por espécies herbáceas e predomínio de espécies arbustivas, lenhosas e espinhentas, como Sophora tomentosa (Leguminosae), Eugenia uniflora e E. nitida (Myrtaceae), além da presença abundante de Neoregelia cruenta e Quesnelia quesneliana (Bromeliaceae), Pilosocereus arrabidae e Cereus fernambucensis (Cactaceae) e indivíduos de Allagoptera arenaria (Arecaceae), atingindo cerca de $1 \mathrm{~m}$ alt.

Nesta região, por influência das correntes oceânicas ascendentes, o clima possui precipitação reduzida e temperaturas moderadas (Martin et al. 1989). A precipitação média anual é de cerca de $800 \mathrm{~mm}$ e a temperatura média anual é de $25^{\circ} \mathrm{C}$, com mínima de $12^{\circ} \mathrm{C}$ e máxima atingindo $36^{\circ} \mathrm{C}$ (Barbiéri 1984); essas condições climáticas propiciam altas taxas de evapotranspiração, gerando deficiência hídrica nos solos da região (FIDERJ 1978).
Metodologia - a praia foi dividida em três áreas cobertas por vegetação herbácea, com fisionomias e relevos distintos, com respectivamente 40, 100 e $150 \mathrm{~m}$ larg. a partir da escarpa praial, denominadas área A, próximo à ponta da praia, com estreita faixa de vegetação herbácea; área $\mathrm{B}$, com vegetação rizomatosa e graminóide e relevo alterado por escavações, e área $\mathrm{C}$, apresentando extenso baixio, ocupado principalmente por gramíneas. A separação das áreas de vegetação herbácea da arbustiva foi estabelecida visualmente, sendo a primeira delimitada pelo início da zona de transição entre ambas, considerando-se aqui como zona de transição a faixa de vegetação pós-praia, paralela à linha da praia, onde as espécies características da vegetação psamófila-reptante passam gradualmente a ocorrer com menor freqüência, frente ao também gradual aumento da freqüência de espécies arbustivas. Essa mudança gradual na composição florística torna a vegetação da zona de transição característica tanto de vegetação herbácea, composta por espécies estoloníferas, rizomatosas e reptantes, quanto de vegetação arbustiva, com espécies lenhosas, de aspecto espinhoso, denso e fechado, modulado pelo vento.

Para a análise estrutural, estas áreas foram amostradas pelo método de parcelas de $1 \mathrm{~m}^{2}$ (MuellerDombois \& Ellenberg 1974), obedecendo a alternância de lados e intervalos de $1 \mathrm{~m}$, lançadas em linhas perpendiculares à linha da praia, a partir da área desnuda da praia, acima da zona de estirâncio, com auxílio de bússola e trena. Em cada parcela foram estimados visualmente, de acordo com Brower \& Zar (1977), os percentuais de área nua (AN), área com cobertura vegetal $(\mathrm{CV})$ de cada espécie encontrada e área coberta por detritos (DET), considerando-se como área de detritos a área do substrato arenoso coberta por elementos destacados do corpo dos indivíduos da parcela, como folhas e flores mortas, galhos secos, frutos e sementes.

Devido às diferentes extensões no comprimento de cada área, o número de linhas e a distância entre elas também foi variado. Nas áreas A e B foram amostradas dez linhas cada uma, com distância de $10 \mathrm{~m}$ entre cada linha. $\mathrm{Na}$ área $\mathrm{C}$, foram amostradas oito linhas, com distância de $20 \mathrm{~m}$ entre cada linha. As áreas amostradas também possuíam larguras distintas da faixa de vegetação herbácea, o que determinou o comprimento de cada linha e, conseqüentemente, o número de parcelas. Assim, na área $\mathrm{A}$ foram amostradas 110 parcelas, 320 na área $B$ e 404 na área $C$.

Após a amostragem das áreas Ae B (junho/1997), forte ressaca atingiu todo o litoral fluminense e a Praia 
do Peró teve sua fisionomia alterada: o avanço das ondas de tempestade destruiu a escarpa praial existente, bem como a cobertura vegetal, escavando uma nova escarpa $20 \mathrm{~m}$ além da escarpa original, destruindo quase completamente a área $\mathrm{A}$ e parcialmente a área $\mathrm{B}$. Desta forma, a amostragem da área $\mathrm{C}$ foi iniciada onde se formou a nova escarpa praial após a referida ressaca; o local destruído após a ressaca é indicado nos perfis topográficos das áreas A e B.

Foram calculados os parâmetros de freqüência absoluta (FA), frequiência relativa (FR), dominância absoluta (DoA), dominância relativa (DoR) e valor de importância (VI) de cada espécie encontrada (Almeida \& Araujo 1997; Menezes \& Araujo 1999). Os dados de densidade das espécies não foram obtidos devido à difícil definição de indivíduo, uma vez que as espécies encontradas eram, muitas vezes, rizomatosas ou com longos caules e ramificações subterrâneas (MuellerDombois \& Ellenberg 1974). Assim, o índice de valor de importância (VI) foi dado a partir da somatória da freqüência e dominância relativas (Pereira et al. 1992; Menezes \& Araujo 1999).

As espécies com maiores VI em cada área tiveram sua distribuição analisada ao longo dos perfis topográficos, pelo cálculo do percentual de sua cobertura média entre as parcelas correspondentes de todos os perfis amostrados; o mesmo foi realizado para análise da variação do percentual de AN, DET e CV. Na comparação entre as áreas, a composição florística foi considerada o atributo básico, utilizando-se para isso o Índice de Similaridade de Sörensen $\left(\mathrm{I}_{\mathrm{S}}\right)$, de acordo com Mueller-Dombois \& Ellenberg (1974).

O material botânico coletado foi depositado no Herbário Alberto Castellanos (GUA), da Fundação Estadual de Engenharia do Meio Ambiente - FEEMA.

Para a análise topográfica, todas as linhas lançadas tiveram seu perfil topográfico traçado com auxílio de clinômetro (marca Suunto, modelo PM-5/360PC) de acordo com método de Garcia \& Piedade (1987), com adaptações (Almeida \& Araujo 1997; Menezes \& Araujo 1999). Todos os perfis tiveram início a partir da área desnuda da praia, acima da zona de estirâncio. Assim, o ponto zero foi considerado em relação aos perfis e não relacionado ao nível do mar. A partir do alinhamento dos perfis topográficos de cada área a partir da escarpa praial, foi verificada certa similaridade topográfica nos perfis dentro de cada uma das áreas, similaridade esta no sentido de coincidir as cristas e depressões no sentido paralelo à linha da praia. Desta forma, optou-se por apresentar, de cada área, o perfil que melhor as representasse. Deve-se ressaltar que os perfis da área
B tiveram sua fisionomia original, ou seja, aquela formada pela ação dos ventos e ondas de tempestade, um pouco alterada, devido a escavações por tratores, $\mathrm{e}$ que os perfis da área $\mathrm{C}$ foram alinhados com os das outras duas áreas, conforme sua posição topográfica original, antes da ressaca. Todos os perfis terminam no início da área de transição entre a vegetação herbácea e a coberta por vegetação arbustiva.

\section{Resultados}

Análise fitossociológica - O total de 38 espécies foi amostrado na área de estudo, sendo 28 identificadas (Tab. 1). As outras dez espécies não puderam ser identificadas devido às más condições do material ou escassez no momento da coleta. A análise fitossociológica global das áreas A, B e C (com inclusão das espécies não identificadas) revela o predomínio de Paspalum maritimum. $\mathrm{Na}$ área $\mathrm{A}$ (Tab. 2), foram registradas 17 espécies, sendo as principais: Paspalum maritimum (VI = 39,17\%), Ipomoea imperati

Tabela 1. Relação das espécies e suas respectivas famílias, amostradas nas formações vegetais herbáceas na Praia do Peró, Cabo Frio, RJ, Brasil.

\begin{tabular}{|c|c|c|}
\hline & Espécies & Família \\
\hline 1. & Acicarpha spatulata $\mathrm{R}$. Br. & Calyceraceae \\
\hline 2. & Allagoptera arenaria (Gomes) O. Ktze. & Arecaceae \\
\hline 3. & Alternanthera maritima (Mart.) A. St.-Hil. & Amaranthaceae \\
\hline 4. & Blutaparon portulacoides (A.St.-Hil.) Mears & Amaranthaceae \\
\hline 5 . & Cenchrus echinatus L. & Poaceae \\
\hline 6. & Cereus fernambucensis Lem. & Cactaceae \\
\hline 7. & Chamaecyse thymifolia (L.) Millsp. & Euphorbiaceae \\
\hline 8. & Commelina sp. & Commelinaceae \\
\hline 9. & Emilia sonchifolia $\mathrm{L}$. & Asteraceae \\
\hline 10. & Eragrostis ciliares Link. & Poaceae \\
\hline 11. & Eugenia uniflora $\mathrm{L}$. & Myrtaceae \\
\hline 12. & Fimbristylis spathacea Roth. & Cyperaceae \\
\hline 13. & Heliotropium sp. & Boraginaceae \\
\hline 14. & Hydrocotyle bonariensis Lam. & Apiaceae \\
\hline & Ipomoea imperati (Vahl.) Griseb & Convolvulaceae \\
\hline & Ipomoea pes-caprae (L.) Sweet & Convolvulaceae \\
\hline & Kyllingia peruviana Lam. & Cyperaceae \\
\hline 18. & Mikania stipulacea Willd. & Asteraceae \\
\hline 19. & Panicum racemosum (Beauv.) Spreng. & Poaceae \\
\hline 20. & Paspalum maritimum Trin. & Poaceae \\
\hline 21. & Polygala cyparissias A. St.-Hil. & Polygalaceae \\
\hline 22. & Remirea marítima Aubl. & Cyperaceae \\
\hline 23. & Scaevola plumieri (L.) Vahl. & Goodeniaceae \\
\hline 24. & Sophora tomentosa $\mathrm{L}$. & Leguminosae \\
\hline 25. & Sporobolus virginicus (L.) Kunth & Poaceae \\
\hline 26. & Stenotaphrum secundatum (Walt.) Kuntze & Poaceae \\
\hline 27. & Vernonia obtusifolia Less. & Asteraceae \\
\hline 28. & Vernonia scorpioides (Lam.) Pers. & Asteraceae \\
\hline
\end{tabular}


Tabela 2. Parâmetros fitossociológicos obtidos para as espécies encontradas na área A (nTP =110), Praia do Peró, Cabo Frio, RJ, Brasil. nTP = número total de parcelas da área; $\mathrm{CT}=$ cobertura total da espécie $\left(\mathrm{m}^{2}\right) ; \mathrm{NP}=$ número de parcelas onde se encontra a espécie; $\mathrm{FR}=$ freqüência relativa do táxon $(\%)$; DoR = dominância relativa do táxon $(\%)$; VI = valor de importância do táxon $(\%)$.

\begin{tabular}{|c|c|c|c|c|c|}
\hline Espécies & CT & NP & $\mathrm{FR}^{*}$ & DoR* & $\mathrm{VI}^{* *}$ \\
\hline 1. Paspalum maritimum & 9,41 & 71 & 12,37 & 26,80 & 39,17 \\
\hline 2. Ipomoea imperati & 4,86 & 96 & 16,73 & 13,84 & 30,57 \\
\hline 3. Ipomoea pes-caprae & 6,72 & 64 & 11,15 & 19,14 & 30,29 \\
\hline 4. Sporobolus virginicus & 5,07 & 83 & 14,46 & 14,44 & 28,90 \\
\hline 5. Hydrocotyle bonariensis & 3,50 & 92 & 16,03 & 9,97 & 26,00 \\
\hline 6. Chamaecyse thymifolia & 1,51 & 54 & 9,41 & 4,30 & 13,71 \\
\hline 7. Stenotaphrum secundatum & 1,73 & 26 & 4,53 & 4,93 & 9,46 \\
\hline 8. Remirea maritima & 0,64 & 31 & 5,40 & 1,82 & 7,22 \\
\hline 9. Acicarpha spatulata & 0,67 & 22 & 3,83 & 1,91 & 5,74 \\
\hline 10. Blutaparon portulacoides & 0,26 & 10 & 1,74 & 0,74 & 2,48 \\
\hline 11. Cereus fernambucensis & 0,42 & 7 & 1,22 & 1,20 & 2,42 \\
\hline 12. Commelina $\mathrm{sp}$. & 0,10 & 6 & 1,05 & 0,28 & 1,33 \\
\hline 13. Indeterminada $1 \mathrm{~A}$ & 0,06 & 5 & 0,87 & 0,17 & 1,04 \\
\hline 14. Allagoptera arenaria & 0,09 & 3 & 0,52 & 0,26 & 0,78 \\
\hline 15. Vernonia scorpiodes & 0,02 & 2 & 0,35 & 0,06 & 0,41 \\
\hline 16. Cenchrus echinatus & 0,03 & 1 & 0,17 & 0,09 & 0,26 \\
\hline 17. Sophora tomentosa & 0,02 & 1 & 0,17 & 0,06 & 0,23 \\
\hline
\end{tabular}

$* \Sigma$ das 17 espécies $=100 \% ; * * \Sigma$ das 17 espécies $=200 \%$

$(\mathrm{VI}=30,57 \%)$, Ipomoea pes-caprae (VI = 30,29\%) e Sporobolus virginicus $(\mathrm{VI}=28,90 \%)$. A alta frequiência de Ipomoea imperati é a responsável pelo seu alto VI, já que ocorre uniformemente ao longo de toda a área A. Paspalum maritimum e Ipomoea pes-caprae encontram-se nesta posição devido às altas coberturas: a primeira domina a região mais afastada do mar e a segunda ocupa mais intensamente a região mais próxima deste (Fig. 1).

Outras espécies que merecem destaque são a Apiaceae Hydrocotyle bonariensis (VI = 26,00\%) que, apesar da baixa dominância, apresenta o segundo maior valor de freqüência da área $\mathrm{A}(\mathrm{FR}=16,03 \%)$, e a Euphorbiaceae Chamaecyse thymifolia, que também apresenta um VI significativo (VI $=13,71 \%$ ) devido aos altos valores de frequiência.

$\mathrm{Na}$ área B (Tab. 3), que apresentava maior movimentação de areia devido a escavações, foram registradas 24 espécies, sendo as dominantes: Paspalum maritimum $(\mathrm{VI}=33,19 \%)$, Panicum racemosum $(\mathrm{VI}$ $=26,95 \%)$, Sporobolus virginicus $(\mathrm{VI}=23,14 \%) \mathrm{e}$ Ipomoea imperati $(\mathrm{VI}=22,48 \%)$, sendo que para estas duas últimas espécies, a frequiência é a responsável pelos altos VI's. O mesmo acontece novamente para Hydrocotyle bonariensis (VI=14,75\%) e Chamaecyse thymifolia $(\mathrm{VI}=14,44 \%)$, que se destacam pelas altas frequiências e baixos valores de dominância. Quanto à Ipomoea pes-caprae, com alto VI na área $\mathrm{A}$, teve $\mathrm{VI}$ mais baixo na área B (VI = 13,98\%), embora continue com alta dominância.

$\mathrm{Na}$ área $\mathrm{C}$ (Tab. 4) foram registradas 27 espécies: as mais importantes foram Paspalum maritimum $(\mathrm{VI}=49,36 \%), \quad$ Stenotaphrum secundatum $(\mathrm{VI}=24,33 \%)$, Fimbristylis spathacea $(\mathrm{VI}=23,71 \%)$ e Sporobolus virginicus (VI $=20,65 \%$ ), sendo que Fimbristylis spathacea não ocorre na área $\mathrm{A}$ e tem baixo VI na área $\mathrm{B}(\mathrm{VI}=3,99 \%)$. Quanto à família Convolvulaceae, apenas Ipomoea pes-caprae foi registrada, com VI muito baixo (VI $=2,30 \%$ ) se comparado aos valores encontrados nas áreas A e B; deve-se no entanto, ressaltar que, devido à ressaca, a região onde esta espécie exibiu maior expressão nas outras duas áreas foi destruída na área C. Ipomoea imperati, com altos VI nas áreas $\mathrm{A}$ e $\mathrm{B}$, não teve ocorrência registrada na área $\mathrm{C}$. Outra espécie que merece destaque é a Remirea maritima $(\mathrm{VI}=15,78 \%)$ que também apresentou alta freqüência $(F R=10,60 \%)$ em comparação à baixa dominância $(\mathrm{DoR}=5,18 \%)$. Hydrocotyle bonariensis ( $\mathrm{VI}=13,33 \%$ ), assim como nas áreas A e B, continuou tendo expressivo valor de frequiência em relação à baixa dominância.

Área nua, detritos e cobertura vegetal - Na estimativa dos percentuais de AN, DET e CV em cada uma das três áreas A (Fig. 1), B (Fig. 2) e C (Fig. 3) estudadas, observou-se gradual declínio de AN conforme ocorria o afastamento em relação ao mar, contrapondo o 
gradual aumento de $\mathrm{CV}$ acompanhada por DET. Na área B (Fig. 2), pode-se observar oscilações no gradual declínio de AN e no aumento de CV e DET conforme ocorria o afastamento em relação ao mar; isto pode ser verificado exatamente nos locais onde havia escavações (aproximadamente aos 30 e $50 \mathrm{~m}$ de distância em relação ao mar), o que provavelmente gerou a alteração deste gradiente. Na área $\mathrm{C}$ (Fig. 3), os valores de CV aumentaram na área de baixio (a partir de $80 \mathrm{~m}$ de distância em relação ao mar), sendo acompanhados
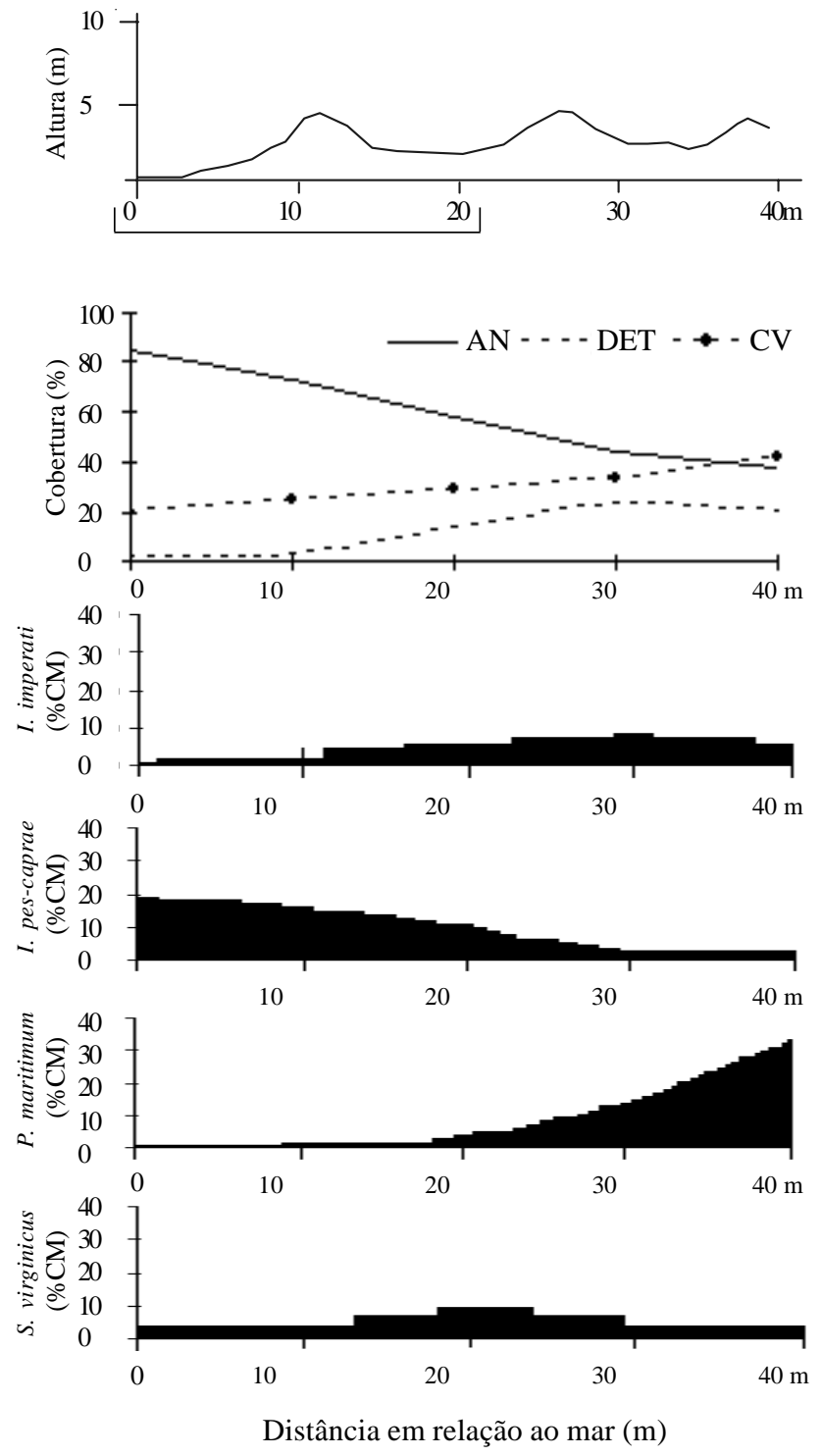

Figura 1. Variação dos percentuais de área nua (AN), cobertura de detritos (DET) e cobertura vegetal (CV) e ocorrência das espécies com maiores VI's de acordo com o percentual de cobertura média (\% $\mathrm{CM})$ ao longo do perfil topográfico mais representativo da área A em função do aumento da distância em relação ao mar, na Praia do Peró, Cabo Frio, RJ, Brasil. A linha abaixo da escala horizontal do perfil topográfico (de 0 a 20 m) indica o local destruído pela ressaca após a amostragem. pelos valores de DET. No final desta área, no entanto (após os $110 \mathrm{~m}$ de distância do mar), terminou o baixio e iniciou-se outra região de dunas, indicada pelo aumento de AN e decréscimo de CV e DET; esta área pós-baixio não foi amostrada devido ao início da ocupação por espécies arbustivas.

Variação da cobertura média das espécies ao longo dos perfis - A cobertura média das espécies com maiores VI distribui-se diferentemente ao longo dos perfis das três áreas estudadas. Paspalum maritimum aumenta gradativamente sua cobertura conforme ocorre afastamento em relação ao mar, enquanto Ipomoea pes-caprae concentra altas coberturas nas regiões próximas ao mar. Assim, estas espécies apresentam distribuição oposta, o que pode ser observado para as áreas A (Fig. 1) e B (Fig. 2). Esta distribuição não parece sofrer influência direta da topografia, uma vez que em ambas as áreas, com topografias distintas, as espécies apresentaram o mesmo comportamento.

Panicum racemosum, que sequer apresentou ocorrência na área $\mathrm{A}$, atingiu altas coberturas ao longo da área B (Fig. 2), com ligeira queda destes valores entre 30-50 m e próximo aos $70 \mathrm{~m}$ de distância do mar; essas regiões correspondem aos locais onde ocorreram escavações de areia. Sporobolus virginicus, que apresentava diminuição da sua cobertura conforme aumentava a distância em relação ao mar, ou seja, ao se aproximar da zona de transição para a comunidade arbustiva [queda de cobertura média a partir dos $30 \mathrm{~m}$ de distância em relação ao mar na área $\mathrm{A}$ (Fig. 1) e a partir dos $60 \mathrm{~m}$ na área B (Fig. 2)], apresenta, na área C (Fig. 3), considerável elevação conforme chega na área de baixio (a $70 \mathrm{~m}$ de distância em relação ao mar), mas decresce ao se aproximar da zona de transição, conforme observado para as áreas A (Fig. 1) e B (Fig. 2). Quanto à Ipomoea imperati, sua distribuição é uniforme na área $\mathrm{A}$ (Fig. 1), sendo que na área B (Fig. 2) possui maior cobertura nas regiões mais próximas do mar.

$\mathrm{Na}$ área C (Fig. 3) observa-se que, mesmo dentro da zona de baixio, localizada a partir de 70 metros de distância do mar, há variações na cobertura das espécies com maiores VI's. Com exceção de Paspalum maritimum, que apresenta alta cobertura com poucas oscilações ao longo de toda a extensão da área $\mathrm{C}$, as outras três espécies, Fimbristylis spathacea, Sporobolus virginicus e Stenotaphrum secundatum demonstraram aumento de cobertura proporcional ao afastamento do mar, atingindo maiores coberturas exatamente no baixio. 
Tabela 3. Parâmetros fitossociológicos obtidos para as espécies encontradas na área B (nTP =320), Praia do Peró, Cabo Frio, RJ, Brasil. nTP = número total de parcelas da área; $\mathrm{CT}=$ cobertura total da espécie $\left(\mathrm{m}^{2}\right) ; \mathrm{NP}=$ número de parcelas onde se encontra a espécie; $\mathrm{FR}=$ freqüência relativa do táxon $(\%) ;$ DoR = dominância relativa do táxon $(\%)$; VI = valor de importância do táxon $(\%)$.

\begin{tabular}{|c|c|c|c|c|c|}
\hline Espécies & CT & NP & $\mathrm{FR}^{*}$ & DoR* & $\mathrm{VI} * *$ \\
\hline 1. Paspalum maritimum & 33,60 & 242 & 12,08 & 21,11 & 33,19 \\
\hline 2. Panicum racemosum & 26,20 & 210 & 10,48 & 16,46 & 26,95 \\
\hline 3. Sporobolus virginicus & 15,69 & 266 & 13,28 & 9,86 & 23,14 \\
\hline 4. Ipomoea imperati & 15,60 & 254 & 12,68 & 9,80 & 22,48 \\
\hline 5. Hydrocotyle bonariensis & 4,73 & 236 & 11,78 & 2,97 & 14,75 \\
\hline 6. Chamaecyse thymifolia & 8,29 & 185 & 9,24 & 5,21 & 14,44 \\
\hline 7. Ipomoea pes-caprae & 14,71 & 95 & 4,74 & 9,24 & 13,98 \\
\hline 8. Stenotaphrum secundatum & 10,23 & 117 & 5,84 & 6,43 & 12,27 \\
\hline 9. Remirea maritima & 4,67 & 161 & 8,04 & 2,93 & 10,97 \\
\hline 10. Cenchrus echinatus & 6,17 & 60 & 3,00 & 3,88 & 6,87 \\
\hline 11. Scaevola plumieri & 7,97 & 21 & 1,05 & 5,01 & 6,06 \\
\hline 12. Acicarpha spatulata & 3,17 & 65 & 3,25 & 1,99 & 5,24 \\
\hline 13. Fimbrystylis spathacea & 3,41 & 37 & 1,85 & 2,14 & 3,99 \\
\hline 14. Cereus fernambucensis & 1,61 & 23 & 1,15 & 1,01 & 2,16 \\
\hline 15. Allagoptera arenaria & 1,59 & 8 & 0,40 & 1,00 & 1,40 \\
\hline 16. Eugenia uniflora & 0,50 & 1 & 0,05 & 0,31 & 0,36 \\
\hline 17. Mikania stipulacea & 0,50 & 1 & 0,05 & 0,31 & 0,36 \\
\hline 18. Commelina sp. & 0,06 & 6 & 0,30 & 0,04 & 0,34 \\
\hline 19. Indeterminada 1B & 0,14 & 4 & 0,20 & 0,09 & 0,29 \\
\hline 20. Emilia sonchifolia & 0,06 & 4 & 0,20 & 0,04 & 0,24 \\
\hline 21. Alternanthera maritima & 0,10 & 3 & 0,15 & 0,06 & 0,21 \\
\hline 22. Blutaparon protulacoides & 0,05 & 2 & 0,10 & 0,03 & 0,13 \\
\hline 23. Heliotropium $\mathrm{sp}$. & 0,06 & 1 & 0,05 & 0,04 & 0,09 \\
\hline 24. Kyllingia peruviana & 0,06 & 1 & 0,05 & 0,04 & 0,09 \\
\hline
\end{tabular}

$* \Sigma$ das 24 espécies $=100 \% ; * * \Sigma$ das 24 espécies $=200 \%$

Composição florística - Na comparação das três áreas A, B e C em relação à sua composição florística através do cálculo do Índice de Similaridade de Sörensen $\left(\mathrm{I}_{\mathrm{S}}\right)$, os resultados obtidos foram: $\mathrm{I}_{\mathrm{S}(\mathrm{A}, \mathrm{B})}=68,3 \%, \mathrm{I}_{\mathrm{S}(\mathrm{B}, \mathrm{C})}=$ $62,7 \%$ e $\mathrm{I}_{\mathrm{S}(\mathrm{A}, \mathrm{C})}=54,5 \%$. Com esses resultados, observase que as áreas contínuas têm maior similaridade florística entre si (A e B; B e C) do que áreas separadas (A e C). Isso mostra que em uma mesma região, a composição florística pode ser muito variada, embora aparente obedecer a uma ocupação contínua e não com intervalos.

Perfis topográficos - Os perfis topográficos apresentam relevo similar no que se refere às cristas e depressões, o que permitiu o seu alinhamento a partir da escarpa praial (Fig. 1 e 2). A faixa indicada de 0 a $20 \mathrm{~m}$ nos perfis das áreas A e B (Fig. 1 e 2) corresponde ao local onde foi verificada a ação da ressaca de junho/1997 e indica, a partir dos $20 \mathrm{~m}$, a formação da nova escarpa praial e o início da amostragem da área C. A extensão dos perfis topográficos corresponde à largura da faixa de vegetação herbácea, terminando no início da área de transição entre esta vegetação e a área coberta por vegetação arbustiva. Nos perfis das áreas A e B, as cristas praiais estão separadas por pequenas depressões, sendo que especificamente na área $\mathrm{B}$, foram detectadas três regiões que sofreram escavações, o que gerou alterações na topografia, originalmente esculpida pelos ventos, ondas de tempestade e marés de sizígia, e na cobertura vegetal, que passou a apresentar maior percentual de área nua. $\mathrm{O}$ perfil da área $\mathrm{C}$ apresenta a nova escarpa praial deslocada $20 \mathrm{~m}$ para o interior em relação à escarpa praial original. Devido à ressaca, toda a faixa frontal desta área foi removida e uma nova escarpa foi criada, com desnível muito mais abrupto, atingindo $6 \mathrm{~m}$ em algumas regiões.

\section{Discussão}

A praia e as comunidades vegetais - A Praia do Peró está constantemente sujeita à ação de ondas de tempestade e marés de sizígia. A escarpa praial com alturas variando entre 0,5 e 4,0 $\mathrm{m}$ sugere a intensidade destes fenômenos na praia. A formação da escarpa impede que ondas de tempestade menos bruscas e marés com menores amplitudes afetem a vegetação frontal localizada sobre ela, agindo como tampão. De 
Tabela 4. Parâmetros fitossociológicos obtidos para as espécies encontradas na área C (nTP =404), Praia do Peró, Cabo Frio, RJ, Brasil. $\mathrm{nTP}=$ número total de parcelas da área; $\mathrm{CT}=$ cobertura total da espécie $\left(\mathrm{m}^{2}\right) ; \mathrm{NP}=$ número de parcelas onde se encontra a espécie; $\mathrm{FR}=$ freqüência relativa do táxon $(\%)$; DoR = dominância relativa do táxon $(\%) ; \mathrm{VI}=$ valor de importância do táxon $(\%)$.

\begin{tabular}{|c|c|c|c|c|c|}
\hline Espécies & $\mathrm{CT}$ & NP & $\mathrm{FR}^{*}$ & DoR* & $\mathrm{VI} * *$ \\
\hline 1. Paspalum maritimum & 77,64 & 389 & 14,94 & 34,42 & 49,36 \\
\hline 2. Stenotaphrum secundatum & 30,02 & 287 & 11,02 & 13,31 & 24,33 \\
\hline 3. Fimbristylis spathacea & 32,16 & 246 & 9,45 & 14,26 & 23,71 \\
\hline 4. Sporobolus virginicus & 24,40 & 256 & 9,83 & 10,82 & 20,65 \\
\hline 5. Remirea maritima & 11,68 & 276 & 10,60 & 5,18 & 15,78 \\
\hline 6. Hydrocotyle bonariensis & 3,91 & 302 & 11,60 & 1,73 & 13,33 \\
\hline 7. Indeterminada $1 \mathrm{C}$ & 9,75 & 173 & 6,64 & 4,32 & 10,97 \\
\hline 8. Acicarpha spatulata & 4,53 & 157 & 6,03 & 2,01 & 8,04 \\
\hline 9. Chamaecyse thymifolia & 3,53 & 157 & 6,03 & 1,57 & 7,59 \\
\hline 10. Panicum racemosum & 11,86 & 58 & 2,23 & 5,26 & 7,49 \\
\hline 11. Polygala cyparissias & 3,88 & 36 & 1,38 & 1,72 & 3,10 \\
\hline 12. Indeterminada $2 \mathrm{C}$ & 1,43 & 55 & 2,11 & 0,63 & 2,75 \\
\hline 13. Ipomoea pes-caprae & 2,51 & 31 & 1,19 & 1,11 & 2,30 \\
\hline 14. Kyllingia peruviana & 2,18 & 34 & 1,31 & 0,97 & 2,27 \\
\hline 15. Cereus fernambucensis & 1,91 & 26 & 1,00 & 0,85 & 1,85 \\
\hline 16. Indeterminada $3 \mathrm{C}$ & 1,01 & 31 & 1,19 & 0,45 & 1,64 \\
\hline 17. Indeterminada $4 \mathrm{C}$ & 1,09 & 25 & 0,96 & 0,48 & 1,44 \\
\hline 18. Cenchrus echinatus & 0,49 & 12 & 0,46 & 0,22 & 0,68 \\
\hline 19. Indeterminada $5 \mathrm{C}$ & 0,16 & 15 & 0,58 & 0,07 & 0,65 \\
\hline 20. Indeterminada 6C & 0,36 & 11 & 0,42 & 0,16 & 0,58 \\
\hline 21. Indeterminada 7C & 0,20 & 10 & 0,38 & 0,09 & 0,47 \\
\hline 22. Vernonia obtusifolia & 0,54 & 5 & 0,19 & 0,24 & 0,43 \\
\hline 23. Indeterminada $8 \mathrm{C}$ & 0,04 & 4 & 0,15 & 0,02 & 0,17 \\
\hline 24. Eragrostis ciliares & 0,03 & 3 & 0,12 & 0,01 & 0,13 \\
\hline 25. Allagoptera arenaria & 0,07 & 2 & 0,08 & 0,03 & 0,11 \\
\hline 26. Scaevola plumieri & 0,15 & 1 & 0,04 & 0,07 & 0,10 \\
\hline 27. Commelina sp. & 0,02 & 2 & 0,08 & 0,01 & 0,09 \\
\hline
\end{tabular}

$* \Sigma$ das 27 espécies $=100 \% ; * * \Sigma$ das 27 espécies $=200 \%$

acordo com Menezes \& Araujo (1999), a ação das vagas na linha da costa proporciona mudanças fisionômicas bastante profundas, influenciando diretamente a estrutura da formação vegetal local, bem como sua largura. A ocorrência de forte ressaca em junho/1997, destruindo totalmente os primeiros 30-40 m da praia e alterando totalmente sua fisionomia, comprova tal dinâmica.

Visualmente, distingue-se na Praia do Peró, as três áreas $\mathrm{A}, \mathrm{B}$ e $\mathrm{C}$ devido às suas diferenças topográficas e fisionomias, e identificam-se duas faixas distintas de vegetação: a frontal, logo sobre a escarpa praial, composta por espécies suculentas e estoloníferas, deixando grandes espaços de areia desnuda; e a posterior, composta basicamente por gramíneas, que recobrem quase todo o terreno. A distribuição da vegetação gerando uma zonação perceptível à primeira vista já foi relatada para outras praias também no Estado do Rio de Janeiro (Magnanini \& Coimbra 1966; Thomaz \& Monteiro 1992).
Alguns trabalhos fazem descrições semelhantes, chamando a comunidade mais próxima do mar de halófila e a comunidade mais adiante, de psamófilareptante (Araujo \& Henriques 1984; Lacerda et al. 1993; Menezes \& Araujo 1999). Diferentemente de Almeida \& Araujo (1997), não foram identificadas duas comunidades distintas, denominadas halófila e psamófila-reptante, porém, a maioria das espécies que compõem estas comunidades (Henriques et al. 1986; Pereira 1990; Lacerda et al. 1993; Thomaz \& Monteiro 1993) foi encontrada na Praia do Peró. Assim, adotouse a denominação psamófila-reptante para ambas as regiões, divididas em "frontal" e "posterior". No entanto, sugere-se a ocorrência de uma comunidade halófila, próxima ao mar, possivelmente destruída antes da formação da escarpa praial por ação de ondas de tempestade: a não recolonização do ambiente pode ter ocorrido como consequiência da ação de fenômenos climáticos de interferência (ondas de tempestade e/ou aumento na amplitude das marés) promovendo 
constante destruição do substrato, impedindo a fixação de qualquer tipo de vegetação (Henriques et al. 1984; Bernardi et al. 1987) ou eliminando a espécie colonizadora (Dansereau 1947; Magnanini 1954).

Os depósitos de areia a barlavento, observados na base da escarpa praial, oriundos dos fortes ventos que atingem a região (FIDERJ 1978) sugerem a formação de substrato adequado para a recolonização do ambiente, diminuindo o abrupto desnível topográfico e originando possivelmente uma comunidade vegetal contínua à escarpa. Na Praia do Peró, a ação de ondas de tempestade parece ser freqüente, impedindo este
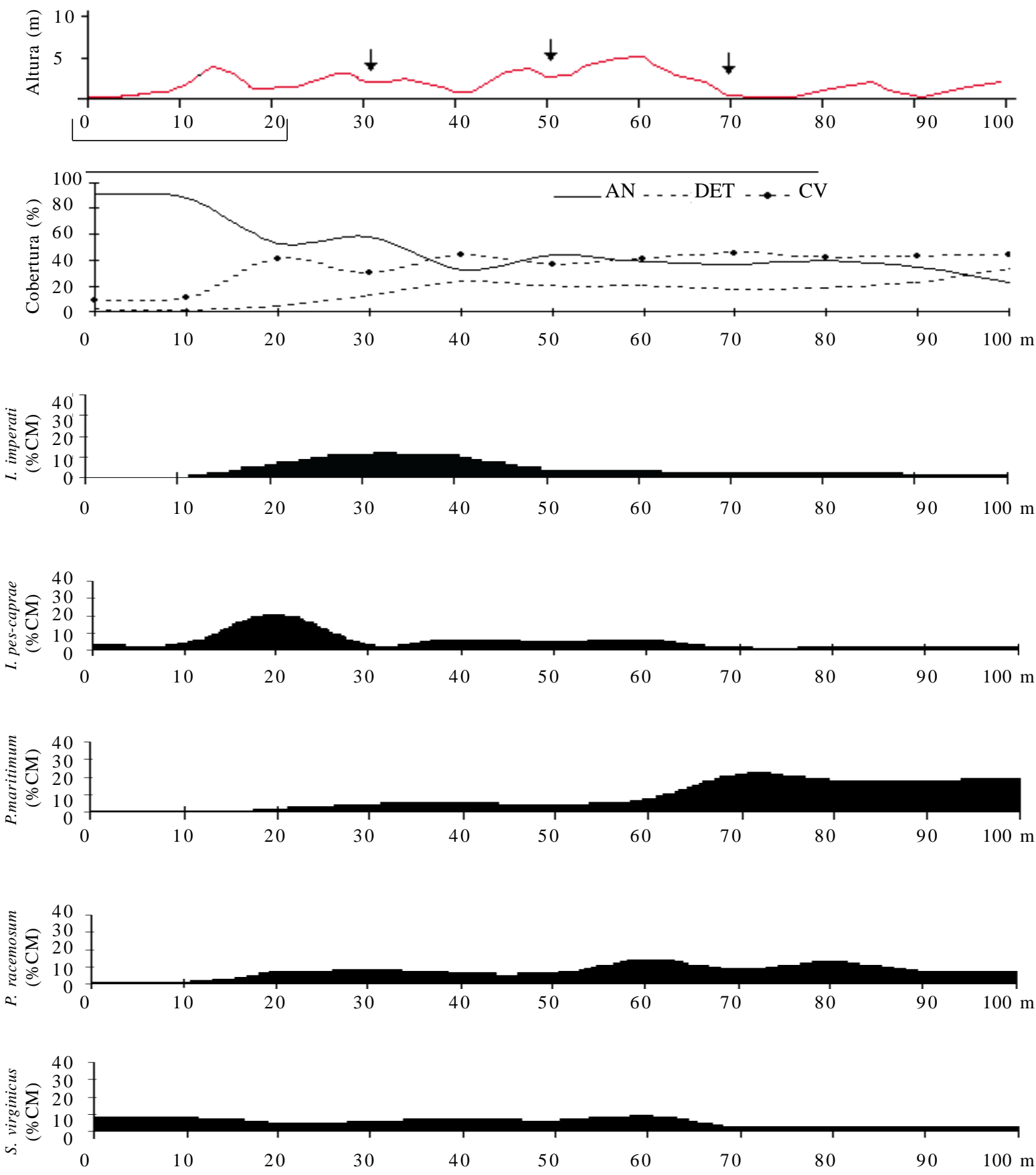

Distância em relação ao mar (m)

Figura 2. Variação dos percentuais de área nua (AN), cobertura de detritos (DET) e cobertura vegetal (CV), e ocorrência das espécies com maiores VI's, de acordo com o percentual de cobertura média (\% CM), ao longo do perfil topográfico mais representativo da área B em função do aumento da distância em relação ao mar, na Praia do Peró, Cabo Frio, RJ, Brasil. A linha abaixo da escala horizontal do perfil topográfico (de 0 a $20 \mathrm{~m}$ ) indica o local destruído pela ressaca após a amostragem. As setas no perfil topográfico indicam os locais onde foram observadas escavações. 
evento, uma vez que, durante o período que compreendeu a amostragem deste trabalho (um ano), os depósitos de areia foram continuamente destruídos, inclusive a parte frontal da escarpa. No entanto, de acordo com Menezes \& Araujo (1999), faz-se necessário o acompanhamento da cobertura vegetal ao longo de vários períodos, observando-se a construção e destruição da região frontal da praia, para que estes processos de interferência sejam realmente compreendidos.

Na região final dos perfis, inicia-se uma mudança gradual da comunidade herbácea para a arbustiva, ocorrendo a sobreposição das espécies destas duas comunidades, formando a chamada zona de transição (Dau 1960; Almeida \& Araujo 1997; Pereira et al. 1992; Menezes \& Araujo 1999).

Análise fitossociológica - Considerando-se as três áreas estudadas, nota-se os altos VI obtidos pelas Poaceae, sendo Paspalum maritimum a espécie dominante. Esta espécie caracteriza-se pela grande capacidade de fixação em regiões onde a movimentação de areia é
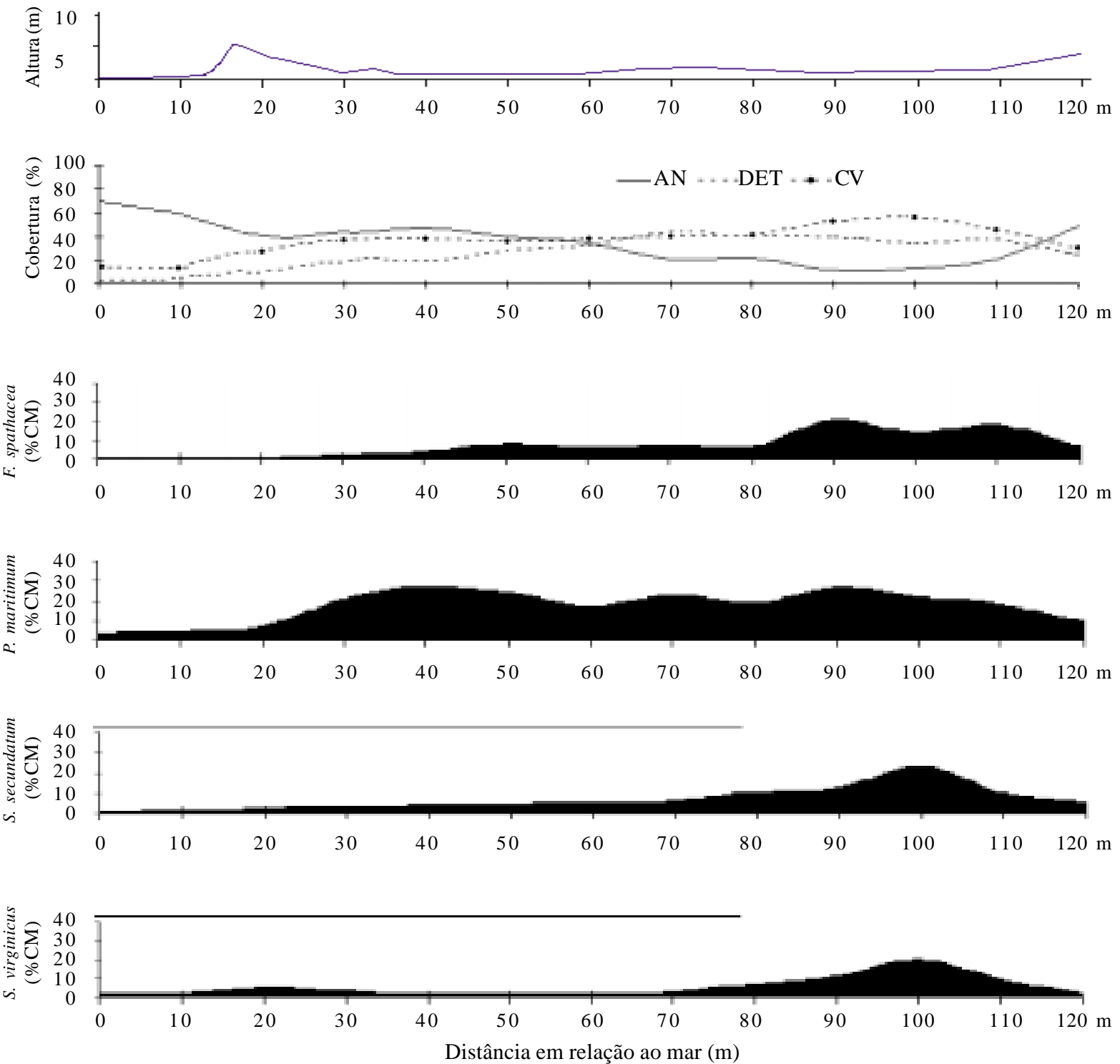

Figura 3. Variação dos percentuais de área nua (AN), cobertura de detritos (DET) e cobertura vegetal (CV) e ocorrência das espécies com maiores VI's de acordo com o percentual de cobertura média $(\% \mathrm{CM})$ ao longo do perfil topográfico mais representativo da área $\mathrm{C}$ em função do aumento da distância em relação ao mar, na Praia do Peró, Cabo Frio, RJ, Brasil. O ponto zero que inicia o perfil topográfico era originalmente alinhado à marca de 20 metros nos perfis das áreas A e B, conforme indicado nas Figuras 1 e 2. 
quase nula, uma vez que o substrato já está ocupado e fixado pela vegetação (Araujo \& Henriques 1984; Henriques et al. 1986; Pereira 1990). Os altos VI obtidos por esta espécie também são explicados pela sua dominância na região posterior da praia, sendo que esta região apresentou extensão muito maior que a ocupada pela região frontal, mais próxima ao mar, onde o predomínio é de espécies estoloníferas. Deve-se ressaltar que esta espécie, dentro do litoral brasileiro, possui registros de ocorrência tanto em regiões frontais (Rizzini 1979) como em dunas fixas (Araujo \& Henriques 1984; Pinto et al. 1984; Almeida \& Araujo 1997).

Na área A destacaram-se também as estoloníferas Ipomoea imperati e Ipomoea pes-caprae, características da zona de transição halófila-psamófila, o que pode sugerir a presença de uma comunidade halófila transitória, destruída continuamente, como suposto anteriormente. Segundo L.F.T. Menezes (dados não publicados), as folhas largas de Ipomoea pes-caprae influenciam sobremaneira a determinação da sua cobertura. De acordo com Andrade (1968), Pfadenhauer (1978) e Cordazzo \& Costa (1989), as espécies estoloníferas ou rizomatosas possuem alta capacidade adaptativa em regiões de alta movimentação de areia, propiciando o crescimento vegetativo, uma vez "que o estabelecimento de novas plântulas através de sementes é reduzido devido às condições ambientais estressantes". Outro fator que corrobora para a ocupação desta região por esta espécie é a resistência a altas temperaturas: uma vez que a área tem pouca cobertura vegetal, a areia fica mais exposta ao sol (Oosting \& Billings 1942). Altos valores de cobertura de Ipomoea pes-caprae nesta região também foram encontrados ao longo de todo o litoral da região sudeste (Ormond 1960; Araujo \& Henriques 1984; Almeida \& Araujo 1997), no nordeste da Bahia (Pinto et al. 1984) e em Santa Catarina, em Garopaba (Cordazzo \& Costa 1989), indicando ampla distribuição na costa brasileira (Hay et al 1981). Ipomoea imperati tem expressiva ocorrência na região sudeste (Andrade 1968; Pereira 1990; Silva \& Somner 1984; Sá 1992). Cabe citar que esta espécie, com altos VI nas áreas A e B, sequer foi registrada na área $\mathrm{C}$, o que mostra distribuição descontínua desta espécie ao longo da praia, embora a região frontal da área $\mathrm{C}$ não tenha sido amostrada devido à ressaca. Deve-se ressaltar, no entanto, que esta espécie apresentou alta frequiência ao longo de toda a extensão das áreas A e B (sentido mar-continente) e não apenas na região frontal, o que não ocorreu na área C. Isso indica que a distância em relação ao mar parece não ser o fator determinante da distribuição desta espécie em particular.

$\mathrm{Na}$ área $\mathrm{B}$, as espécies que se destacaram foram Panicum racemosum e Sporobolus virginicus, características da comunidade psamófila-reptante (Henriques et al. 1986). Panicum racemosum tem ocorrência significativa em outras regiões do litoral brasileiro, principalmente em áreas próximas ao mar e com muita movimentação de areia (Pfadenhauer 1978; Costa et al. 1984; Costa et al. 1991) o que justamente caracteriza a área B. Segundo Costa et al. (1996), o acréscimo de areia, oriundo de ação eólica ou antrópica, controla a germinação das sementes desta espécie e o estabelecimento da plântula, daí a preferência por estas áreas. Devido a esta característica, esta espécie age como pioneira, formadora e fixadora de dunas (Dansereau 1947; Henriques et al. 1984; Cordazzo \& Costa 1989; Cordazzo \& Seeliger 1993).

Na Praia do Peró, as altas coberturas desta espécie, principalmente ao redor de locais com escavações de areia, podem sugerir a formação de grupos de indivíduos iniciando atividade fixadora de dunas. A queda dos valores de frequiência e cobertura observada nas zonas de baixio (área C) sugere possível perda do vigor da planta, o que pode ser explicado pelo baixio encontrarse sobre dunas fixas ou pela maior distância em relação ao mar, embora esta espécie também tenha obtido abundância na chamada Formação Graminóide com Arbustos, em Carapebus, Rio de Janeiro (Henriques et al. 1986), zona de dunas já fixas. Ao longo do litoral brasileiro, pode-se encontrar outras regiões com ocorrência significativa de Panicum racemosum: as praias do nordeste da Bahia (Pinto et al. 1984), Rio de Janeiro (Hay et al. 1981), Espírito Santo (Pereira 1990), e dunas frontais da costa sul: Santa Catarina (Cordazzo \& Costa 1989) e Rio Grande do Sul (Cordazzo \& Davy 1997).

Sporobolus virginicus possui a maior freqüência relativa dentre as espécies encontradas na área $\mathrm{B}$, com altas coberturas nas regiões frontais e nas zonas escavadas. Tem ocorrência significativa nas comunidades praianas ao longo da costa brasileira (Seabra 1949; Andrade \& Lamberti 1965; Araujo \& Henriques 1984), sendo menos freqüente nas dunas da costa sul, onde esta espécie é substituída fitogeograficamente, em associações psamófilas de dunas frontais pela Asteraceae Senecio crassiflorus (Lam.) DC. (Cordazzo \& Costa 1989). A distribuição desta espécie também se alastra por outras regiões tropicais (Gooding 1947) e subtropicais (Breen et al. 1977). Sporobolus virginicus apresenta-se como uma espécie fixadora de dunas (Hueck 1955; Pereira 
1990): na Praia do Peró essa característica foi registrada devido às altas freqüências e coberturas ao redor das regiões escavadas, juntamente com Panicum racemosum.

Stenotaphrum secundatum, uma das espécies dominantes da área $\mathrm{C}$, é uma espécie característica da comunidade psamófila-reptante (Araujo \& Henriques 1984). Esta espécie é considerada acumuladora de matéria orgânica, pois suas folhas mortas não são facilmente arrastadas pelo vento, gerando acúmulo de matéria orgânica em começo de decomposição (Ormond 1960). Esta característica foi observada na Praia do Peró, onde as regiões com alta cobertura de Stenotaphrum secundatum coincidem com as áreas de alta cobertura de detritos. Ocorrências de Stenotaphrum secundatum foram citadas em estudos fitossociológicos realizados nas comunidades praianas de São Paulo (Hueck 1955), Bahia (Seabra 1949), Rio de Janeiro (Araujo \& Henriques 1984) e Espírito Santo (Pereira 1990).

Fimbristylis spathacea aparece na área $\mathrm{C}$ com o terceiro maior VI, após inexpressiva ocorrência na área $\mathrm{B}$ e ausência na área A, revelando que a uniformidade de ocupação do substrato é apenas visual, já que a espécie Ipomoea imperati também apresentou distribuição descontínua ao longo da extensão da praia. Para Fimbristylis spathacea, no entanto, a distância em relação ao mar parece ser relevante nesta distribuição, pois tem cobertura muito baixa na região frontal amostrada na área $\mathrm{C}$ e alta cobertura na região de baixada. Ocorrência desta espécie em regiões mais afastadas do mar, sujeitas à inundação em épocas de chuva, como no baixio da área $\mathrm{C}$, foram observadas por Araujo \& Henriques (1984) no litoral norte fluminense, Cabo Frio e Araruama.

Deve-se destacar que, na área $\mathrm{C}$, Stenotaphrum secundatum e Fimbristylis spathacea, além de Sporobolus virginicus, tiveram variações na sua cobertura mesmo dentro da região de baixio, atingindo altos valores entre 80 e 110 metros de distância a partir do mar. No entanto, sem a disponibilidade de dados sobre fatores ambientais desta região, não se pode justificar o porquê deste comportamento, mas possivelmente a distância do mar e a profundidade do lençol freático atuam como fatores determinantes.

Outras espécies que merecem citação pelos VI significativos devido à alta freqüência e baixa dominância, são Hydrocotyle bonariensis, nas áreas A, B e C; Chamaecyse thymifolia, nas áreas A e B; e Remirea maritima na área $\mathrm{C}$.

Hydrocotyle bonariensis é espécie característica da região de dunas móveis, sujeitas à ação de ondas e ventos fortes. Apresenta caule subterrâneo e sistema radicular extenso, facilitando o rápido crescimento vegetativo (Cordazzo \& Seeliger 1993), o que permite sua resistência à movimentação de areia (Andrade 1968; Pfadenhauer 1978). Na Praia do Peró, esta espécie destaca-se pela alta frequiência em todas as três áreas estudadas. Resultados semelhantes, onde a espécie apresenta altos índices de frequiência, foram encontrados por Cordazzo \& Costa (1989) nas dunas frontais de Garopaba, Santa Catarina, e nas dunas frontais e fixas da região sul do Rio Grande do Sul (Cordazzo \& Seeliger 1993; Costa et al. 1996). Esta espécie tem ampla distribuição geográfica, sendo encontrada nas comunidades de dunas da região sudeste (Hay et al. 1981; Araújo \& Henriques 1984) e nordeste do país (Pinto et al. 1984).

Chamaecyse thymifolia é espécie característica de dunas frontais, onde é comumente encontrada na região sudeste (Dansereau 1947; Henriques et al. 1984) e nordeste brasileiro (Pinto et al. 1984), mas possui ocorrências na vegetação arbustiva de Palmae, em Saquarema (Sá 1992) e na Restinga da Marambaia (Menezes \& Araújo 1999), ambas no Rio de Janeiro. Dados de alta frequiência em comparação à baixa dominância, como os encontrados no Peró, foram relatados por Almeida \& Araújo (1997) em Saquarema, RJ.

Remirea maritima é uma espécie cuja principal característica é a grande resistência à movimentação de areia: possui alta propagação vegetativa (Dansereau 1947) e sistema radicular extenso, que se estende sob a areia em direções que são evidenciadas pelos brotos que se formam, distanciados uns dos outros (Andrade 1968). Essa característica permite que a espécie seja facilmente encontrada tanto na região de dunas frontais como em dunas fixas, ao longo do litoral brasileiro (Rawitscher 1944; Araújo \& Henriques 1984; Pinto et al. 1984; Cordazzo \& Costa 1989). Dados semelhantes de alta frequiência e baixa dominância desta espécie, obtidos na Praia do Peró, foram relatados para a costa sudeste (Henriques et al. 1984; Menezes \& Araújo 1999) e sul do país (Cordazzo \& Costa 1989).

Área coberta por vegetação, área nua e detritos - Nas áreas A e B, entre 0 e $40 \mathrm{~m}$ de distância do mar, a queda dos valores de AN se dá conforme ocorre o afastamento do mar, uma vez que as condições ambientais vão se tornando menos adversas e contribuem para o desenvolvimento da vegetação: diminuição da ação das marés, diminuição de chegada de salsugem e, por consequiência da ocupação vegetal, menor movimentação de areia (Cordazzo \& Costa 
1989). A partir disso, pode-se concluir que a área $C$, que não teve sua região frontal amostrada devido à ressaca que atingiu a Praia do Peró destruindo os primeiros $20 \mathrm{~m}$ de dunas ali existentes, possivelmente obedecia às determinações feitas para as duas outras áreas no que se refere ao percentual de CV e AN. Nesta área, a partir dos 30-40 m de distância do mar, onde se inicia a região de baixada, os percentuais de DET e CV são muito altos e muito próximos. Considerando-se que a região de baixada é composta praticamente por plantas graminóides, estes resultados podem ser explicados, já que, segundo Ormond (1960), plantas graminóides acumulam muitos detritos, como folhas mortas e matéria orgânica em decomposição.

Assim, pode-se concluir que a distância do mar parece ser a maior responsável pela distribuição da vegetação observada na Praia do Peró e sua zonação, sendo que interferências de caráter ocasional, tais como escavações e ressacas, podem contribuir para sua modificação, dificultando a análise dos fatores que a determinam; por outro lado, estas interferências podem servir de instrumento para que se determine como se dá a reestruturação da comunidade em questão.

Composição florística - O cálculo do Índice de Similaridade de Sörensen $\left(\mathrm{I}_{\mathrm{S}}\right)$ na comparação das três áreas $\mathrm{A}, \mathrm{B}$ e $\mathrm{C}$ revela maior similaridade entre áreas contínuas (A e B; B e C) do que entre áreas separadas (A e C), mostrando que em uma mesma região, embora a composição florística seja variada, parece obedecer a uma ocupação contínua, e não com intervalos.

Além das áreas A e B possuírem a maior similaridade florística entre si $\left(\mathrm{I}_{\mathrm{S}}=68,3 \%\right)$, deve-se citar que possuem também a maior similaridade topográfica, uma vez que não possuem o baixio, característico da área C. No entanto, as áreas A e B tiveram amostradas as regiões mais próximas do mar, o que não aconteceu com a área $\mathrm{C}$, cuja zona originalmente mais próxima do mar foi destruída pela ressaca antes da amostragem. A ausência de Ipomoea imperati na área $\mathrm{C}$, após apresentar altos VI nas áreas A e B, pode ser consequiência da impossibilidade de amostragem da zona frontal da área $\mathrm{C}$ e não uma interrupção na sua distribuição ao longo da praia.

Considerando que a área em estudo caracteriza-se como uma comunidade psamófila-reptante, cabe citar que, dentre as espécies identificadas que apresentaram ocorrência restrita a apenas uma das áreas, várias são características de outras comunidades vegetais que não a psamófila-reptante. Dentre estas espécies com ocorrência restrita a apenas uma das áreas amostradas na Praia do Peró tem-se Sophora tomentosa, característica da comunidade arbustiva pós-praia e Emilia sonchifolia, Eugenia uniflora, Mikania stipulacea, Vernonia obtusifolia e Vernonia scorpioides, comumente encontradas na comunidade arbustiva de Palmae (Araujo \& Henriques 1984; Silva \& Somner 1984; Menezes \& Araujo 1999).

Influência da topografia - A partir da análise da variação da cobertura média das espécies com maiores VI ao longo dos perfis, pode-se observar que as espécies analisadas têm distribuição espacial determinada pela distância em relação ao mar, formando um gradiente próprio para cada espécie, no sentido mar-continente. Esta distribuição independe da topografia do terreno, onde ocorre qualquer uma das espécies analisadas, desde que em regiões com topografias distintas, a distribuição das espécies se manteve inalterada; e em regiões com topografia similar, como no baixio da área C, ocorrem variações na distribuição das espécies presentes. Por outro lado, algumas regiões da área B tiveram sua topografia alterada devido à abertura de buracos por escavações que removeram a vegetação; nestas regiões, nota-se o estabelecimento de uma nova comunidade vegetal que, neste caso, independe da distância em relação ao mar, mas sim é determinada pela ação de espécies colonizadoras, como Sporobolus virginicus e Panicum racemosum, que atuam como pioneiras e fixadoras de dunas (Henriques et al. 1984; Pereira 1990; Cordazzo \& Seeliger 1993).

Dansereau (1947), em trabalho sobre zonação e sucessão nas restingas do Rio de Janeiro, observa que as comunidades vegetais colonizam o terreno respondendo às condições topográficas. $\mathrm{Na}$ área $\mathrm{B}$ da Praia do Peró as escavações provocaram alteração topográfica em conjunto com alterações edáficas, pois houve remoção da cobertura vegetal e de grande parte do substrato. Neste caso, não é possível afirmar que a comunidade vegetal estabelecida a partir de então foi determinada apenas pela alteração das condições topográficas, uma vez que não foram coletados dados sobre composição do solo antes e depois das escavações. Outros trabalhos relatam a influência da topografia na determinação das comunidades vegetais: Oosting \& Billings (1942) destacam as elevações do terreno como barreiras para a chegada da salsugem na comunidade localizada a sotavento e Earle \& Kershaw (1989) afirmam que as elevações e descidas do terreno influenciam indiretamente a estrutura da comunidade, uma vez que determinam os locais de possíveis inundações e estabelecem as relações entre a planta e 
o lençol freático.

Quanto à dinâmica topográfica formadora do terreno, os repetidos processos de destruição da região frontal da praia e de reposição da areia levada pelas ressacas, bem como a recolonização da praia pela cobertura vegetal, parecem ser os fatores mais atuantes no processo de formação da paisagem. Exemplo disso é que, ao longo dos perfis analisados, principalmente na área $\mathrm{A}$, que durante a amostragem não sofreu alterações por ação de escavações ou ressacas parciais, observa-se uma repetição da composição topográfica para grande extensão da praia. Este mesmo processo foi relatado por Menezes \& Araujo (1999) para o cordão externo da Restinga da Marambaia, RJ.

Desta forma, a topografia, determinada pela ação de fenômenos de interferência (tempestades e marés com altas amplitudes), pelo aporte de areia oriundo dos ventos e das marés e pela ação antrópica, é aqui considerada como um componente influente na paisagem, mas não determinante, estabelecido em conjunto com a comunidade vegetal, sendo esta última fortemente determinada pela distância que se encontra em relação ao mar.

Visando os objetivos propostos no início deste trabalho, de caracterizar as áreas estudadas quanto à sua composição florística e posição topográfica, verificando os processos que influenciam sua distribuição e determinam a paisagem, e tendo como base os resultados obtidos e discutidos, pode-se concluir primeiramente, que a estrutura da vegetação (composição florística e distribuição) em regiões de dunas ativas (áreas A e B) é extremamente variável, compondo um mosaico de espécies que se distribuem, a princípio, obedecendo a zonação paralela à linha da praia, sendo bastante influenciada pela distância em que se encontra do mar. A distância do mar parece contribuir para a distribuição da vegetação em zonas sem dunas, como o baixio (área $\mathrm{C}$ ): embora não ocorra alteração na sua topografia e fisionomia, sua estrutura é diversificada.

Por apresentar a cobertura vegetal disposta em zonas paralelas à linha da praia (zonação), a composição florística no sentido perpendicular a esta linha é muito variável, formando um gradiente, com substituição e aumento no número de espécies na direção marcontinente.

Quanto à composição florística ao longo da extensão da praia, observou-se descontinuidade na distribuição de algumas espécies com altos VI dentro da mesma faixa de zonação (Panicum racemosum, Fimbristylis spathacea e Ipomoea imperati), sem que fossem identificados os fatores que a determinam.
Mesmo assim, pôde-se concluir que áreas adjacentes possuem maior similaridade florística (A e B; B e C) que áreas separadas (A e C). Isso mostra que em uma mesma região, embora a composição florística possa ser muito variada, a ocupação de espécies parece ser contínua e não com intervalos; isso pode ser exemplificado pela presença de algumas espécies em apenas uma área e pelas espécies presentes em mais de uma área ocorrendo sempre em áreas adjacentes e nunca em áreas separadas.

Em relação às interferências ocasionais observadas na Praia do Peró (escavação de areia e ressacas), podese concluir que a comunidade vegetal de dunas é uma comunidade extremamente dinâmica e altamente resiliente. $\mathrm{O}$ rápido re-estabelecimento da cobertura vegetal pôde ser constatado pelas altas coberturas de espécies com características colonizadoras, como Panicum racemosum e Sporobolus virginicus ao redor de locais que sofreram interferência. Em relação à topografia, observou-se que ela se estabelece em conjunto com a comunidade vegetal, sem a determinar, função esta desempenhada pela distância da comunidade em relação ao mar.

\section{Referências bibliográficas}

Almeida, A.L. \& Araujo, D. S. D. 1997. Comunidades vegetais do cordão arenoso externo da Reserva Ecológica Estadual de Jacarepiá, Saquarema, RJ. Oecologia Brasiliensis 3: 47-63.

Andrade, M.A.B. \& Lamberti, A. 1965. A vegetação. Pp. 151200. In: A Baixada santista. Aspectos Geográficos. São Paulo, EDUSP.

Andrade, M.A.B. 1968. Contribuição ao conhecimento da ecologia das plantas das dunas do litoral do Estado de São Paulo. Boletim da Faculdade de Filosofia Ciências e Letras da USP 305(22): 3-170.

Araujo, D.S.D. 1992. Vegetation types of sandy coastal plains of tropical Brazil: a first approximation. Pp. 337-347. In: U. Seeliger (ed.). Coastal Plant Communities of Latin America. New York, Academic Press.

Araujo, D.S.D. \& Henriques, R.P.B. 1984. Análise florística das restingas do Estado do Rio de Janeiro. Pp. 159-193. In: L.D. Lacerda; D.S.D. Araujo; R. Cerqueira \& B. Turcq (orgs.). Restingas: Origem, Estrutura e Processos. Niterói, CEUFF.

Barbiéri, E.B. 1984. Cabo Frio e Iguaba Grande, dois microclimas distintos a um curto intervalo espacial. Pp. 3-13. In: L.D. Lacerda; D.S.D. Araujo; R. Cerqueira \& B. Turcq (orgs.). Restingas: Origem, Estrutura e Processos. Niterói, CEUFF.

Bernardi, H.; Cordazzo, C.V. \& Costa, C.S.B. 1987. Efeito de ressacas sobre Blutaparon portulacoides (St. Hill) Mears, nas dunas costeiras do sul do Brasil. Ciência e Cultura 39(5/6):545-547. 
Breen, C.M.; Everson, C. \& Rogers, K. 1977. Ecological studies on Sporobolus virginicus (L.) Kunth with particular reference to salinity and inundation. Hydrobiology 54: $135-140$.

Britto, I.C. \& Noblick, L.R. 1984. A importância de preservar as dunas de Itapoã e Abaeté. Pp. 269-273. In: L.D. Lacerda; D.S.D. Araujo; R. Cerqueira \& B. Turcq (orgs.). Restingas: origem, estrutura e processos. Niterói, CEUFF.

Brower, J.E. \& Zar, J.H. 1977. Field and laboratory methods

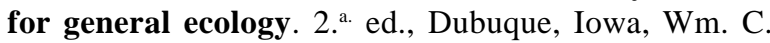
Brown Co.

Cordazzo, C.V. \& Costa, C.S.B. 1989. Associações vegetais das dunas frontais de Garopaba (SC). Ciência e Cultura 41(9): $906-910$

Cordazzo, C.V. \& Davy, A.J. 1997. Effects of Temperature and Light on Seed Germination in the Dune-Building Grass Panicum racemosum Spreng. Atlântica 19: 87-97.

Cordazzo, C.V. \& Seeliger, U. 1987. Composição e distribuição da vegetação nas dunas costeiras ao sul de Rio Grande (RS). Ciência e Cultura 39(3): 321-324.

Cordazzo, C.V. \& Seeliger, U. 1993. Zoned Habitats of Southern Brazilian Coastal Foredunes. Journal of Coastal Research 9(2): 317-323

Costa, C.S.B.; Cordazzo, C. \& Seeliger, U. 1996. Shore Disturbance and Dune Plant Distribution. Journal of Coastal Research 12(1): 133-140.

Costa, C.S.B.; Seeliger, U. \& Cordazzo, C.V. 1984. Aspectos da ecologia populacional do Panicum racemosum Spreng. nas dunas costeiras do Rio Grande do Sul, Brasil. Pp. 395-411. In: L.D. Lacerda; D.S.D. Araujo; R. Cerqueira \& B. Turcq (orgs.). Restingas: origem, estrutura e processos. Niterói, CEUFF.

Costa, C.S.B.; Seeliger, U. \& Cordazzo, C.V. 1991. Leaf demography and decline of Panicum racemosum populations in coastal foredunes of southern Brazil. Canadian Journal of Botany 69: 1593-1599.

Dansereau, P. 1947. Distribuição de zonas e sucessão nas restingas do Rio de Janeiro. Boletim Geográfico 60: 1431-1433.

Dau, L. 1960. Microclimas das Restingas do Sudeste do Brasil, I. Restinga Interna de Cabo Frio. Arquivos do Museu Nacional 50: 79-133.

Earle, J.C. \& Kershaw, K.A. 1989. Vegetation patterns in James Bay coastal marshes, III. Salinity and elevation as factors influencing plant zonations. Canadian Journal of Botany 67: 2967-2974.

FEEMA - Fundação Estadual de Engenharia e Meio Ambiente. 1988. Importância da biota da região de Cabo Frio. Rio de Janeiro, FEEMA.

FIDERJ. 1978. Indicadores climatológicos do Rio de Janeiro. Rio de Janeiro, FIDERJ.

Garcia, G.J. \& Piedade, G.C.R. 1987. Topografia aplicada às ciências agrárias. $5^{\text {a }}$ ed., São Paulo, Nobel.

Gooding, E.G.B. 1947. Observations of the sand dunes of Barbados, British West Indies. Journal of Ecology 34: 111-125.

Hay, J.D.; Henriques, R.P.B. \& Lima, D.M. 1981. Quantitative comparisions of dune and foredune vegetation in restinga ecosystems in the state of Rio de Janeiro. Revista Brasileira de Biologia 41(3): 655-662.
Henriques, R.P.B.; Araujo, D.S.D. \& Hay, J.D. 1986. Descrição e classificação dos tipos de vegetação da restinga de Carapebus, Rio de Janeiro. Revista Brasileira de Botânica 9: 173-189.

Henriques, R.P.B.; Meirelles, M.L. \& Hay, J.D. 1984. Ordenação e distribuição de espécies das comunidades vegetais na praia da restinga de Barra de Maricá, Rio de Janeiro. Revista Brasileira de Botânica 7: 27-36.

Hueck, K. 1955. Plantas e a formação organogênica das dunas no litoral paulista I. Contribuição para a pesquisa fitossociológica paulista 2. São Paulo, Secretaria da Agricultura, Instituto de Botânica.

Lacerda, L.D.; Araujo, D.S.D. \& Maciel, N.C. 1993. Dry coastal ecosystems of the tropical Brazilian coast. Pp. 477-493. In: E. van der Maarl (ed.). Dry coastal ecosystems of the world. Amsterdam, Elsevier.

Magnanini, A. 1954. Contribuição ao estudo das zonas de vegetação da praia de Sernambetiba, DF. Arquivos do Serviço Florestal 8: 147-232.

Magnanini, A. \& Coimbra, A.F. 1966. As praias do estado da Guanabara. Boletim Geográfico 189: 877-890.

Martin, L.; Flexor, J.M. \& Valentin, J.L. 1989. The influence of the "El Niño" phenomenon on the enhancement or annihilation of Cabo Frio upwelling on the Brazilian coast of the State of Rio de Janeiro. Pp. 225-227. In: International Symposium on Global Changes in South America during the Quaternary. São Paulo, Associação Brasileira de Estudos do Quaternário.

Menezes, L.T.F. \& Araujo, D.S.D. 1999. Estrutura de duas formações vegetais no cordão externo da Restinga da Marambaia, RJ. Acta Botanica Brasilica 13(2): 223-235.

Menezes, L.F.T. \& Araujo, D.S.D. 2000. Variação da biomassa área de Allagoptera arenaria (Gomes) O. Kuntze (Arecaceae) em comunidade arbustiva de Palmae na restinga de Marambaia, RJ. Revista Brasileira de Biologia 60(1): 147-157.

Mueller-Dombois, D. \& Ellenberg, H. 1974. Aims and methods of vegetation Ecology. New York, John Wiley \& Sons.

Oosting, H.J. \& Billings, W.D. 1942. Factors affecting vegetational zonation on coastal dunes. Ecology 23(2): 131-142.

Ormond, W.T. 1960. Ecologia das restingas do sudeste do Brasil - Comunidades vegetais das praias arenosas. Arquivos do Museu Nacional 50: 185-236.

Pereira, O.J. 1990. Caracterização fito-fisionômica da restinga de Setiba, Guarapari, Espírito Santo, v.3. Pp. 207-219. In: Anais do II Simpósio de Ecossistemas da Costa Sul e Sudeste Brasileira: Estrutura, Função e Manejo. Águas de Lindóia. São Paulo, ACIESP.

Pereira, O.J.; Thomaz, L.D. \& Araujo, D.S.D. 1992. Fitossociologia da vegetação de antedunas da restinga de Setiba/Guarapari e em Interlagos/Vila Velha, ES. Boletim do Museu de Biologia Mello Leitão (Nova Série) 1: 65-75.

Pfadenhauer, J. 1978. Contribuição ao conhecimento da vegetação e de suas condições de crescimento nas dunas costeiras do Rio Grande do Sul. Revista Brasileira de Biologia 38(4): 827-836. 
Pinto, G.C.P.; Bautista, H.P. \& Ferreira, J.D.C.A. 1984. A Restinga do litoral nordeste do Estado da Bahia. Pp. 195-216. In: L.D. Lacerda; D.S.D. Araujo; R. Cerqueira \& B. Turcq (orgs.). Restingas: origem, estrutura e processos. Niterói, CEUFF.

Rawitscher, F. 1944. Algumas noções sobre a vegetação do litoral brasileiro. Boletim da Associação Geográfica Brasileira 4(5): 13-28.

Rizzini, C.T. 1979. Tratado de Fitogeografia do Brasil. Aspectos sociológicos e florísticos. v.2., São Paulo, HUCITEC.

Sá, C.F.C. 1992. A vegetação da Restinga de Ipitangas, Reserva Ecológica Estadual de Jacarepiá, Saquarema (RJ). Arquivos do Jardim Botânico do Rio de Janeiro 31: 97-102.
Seabra, J.J.A. 1949. Flora das dunas. Lilloa 20: 187-192.

Seeliger, U. 1992. Coastal foredunes of southern Brazil: physiography, habitats and vegetation. Pp. 367-381. In: U. Seeliger (ed.). Coastal Plant Communities of Latin America. New York, Academic Press.

Silva, J.G. \& Somner, G.V. 1984. A vegetação da Restinga na Barra de Maricá, RJ. Pp. 217-226. In: L.D. Lacerda; D.S.D. Araujo; R. Cerqueira \& B. Turcq (orgs.). Restingas: origem, estrutura e processos. Niterói, CEUFF.

Thomaz, L.D. \& Monteiro, R. 1992. Uma revisão da comunidade halófila-psamófila do litoral brasileiro. Boletim do Museu de Biologia Mello Leitão (Nova Série) 1: 103-114.

Thomaz, L.D. \& Monteiro, R. 1993. Distribuição das espécies na comunidade halófila-psamófila ao longo do litoral do Espírito Santo. Arquivos de Biologia e Tecnologia 36(2): 375-399. 
